\title{
Qualitative and quantitative analysis of the content of phenolic compounds and their derivatives in the rhizome of Panax vietnamensis Ha et Grushv
}

\author{
C Roman O. Grigoryev, ${ }^{1+}$ Nadezhda K. Chirikova, ${ }^{2} *$ and Daniil N. Olennikov ${ }^{3}$ \\ ${ }^{1}$ Laboratory of Biology of Cultured Cells. Timiryazev Institute of Plant Physiology of RAS. Moscow, 127276. \\ Botanicheskaya St., 35. Russia. Phone: +7 (9151) 99-24-26.E-mail:1991grom22@gmail.com \\ ${ }^{2}$ Department of Biology. Ammosov North-Eastern Federal University. Yakutsk, 677000. Russia. \\ ${ }^{3}$ Laboratory of Medical and Biological Research. Institute of General and Experimental Biology. \\ Siberian Branch, Russian Academy of Sciences. Ulan-Ude, 670047. Russia.
}

Keywords: vcietnamese ginseng, Panax vietnamensis, phenolic compounds, rhizome.

\begin{abstract}
Since ancient times, it is known that all types of ginseng were widely used in Eastern folk medicine as a cure for many diseases. All species of the genus Panax, including Panax vietnamensis, contain saponins, but the phenolic composition has not been studied to date. Vietnamese ginseng is characterized by a unique composition of triterpene glycosides, among which the glycosylated derivatives of the rare triterpene aglycone, okothylol, are predominant. It is the only evergreen among ginsengs. As you know, a single plant can have different types of biological activity due to the content of different groups of biologically active compounds with a wide range of physicochemical properties and causing different pharmacological effects. Obviously, phenolic compounds along with other secondary metabolites in Panax vietnamensis have a phytotherapeutic effect on the human body. The purpose of this work is to expand the knowledge of the scientific community about the synthesized compounds, in particular about phenolic compounds that accumulate in the rhizomes of Panax vietnamensis. In this paper, the results of a study on the qualitative (method HPLC-DMD-MS) and quantitative content of phenolic compounds (Folin-Cicalteu method) of the roots of Panax vietnamensis were presented for the first time. These results can be very interesting for scientists involved in the synthesis of secondary metabolites, growing callus and suspension cell cultures in vitro ginseng and other ginseng species, as well as for pharmaceutical and cosmetic companies producing various consumer products for the population based on Vietnamese ginseng. This work will expand the scientific community's knowledge of secondary metabolites synthesized by the rhizome Panax vietnamensis Ha et Grushv.
\end{abstract}

\section{References}

[1] H.T. Zung, I.V. Grushvisky (): A new species of the genus Panax L., Araliaceae in Vietnaum: Panax vietnamensis Ha et Grushv. Bot J Vietnam 70. 1985. P.518-522. DOI: 10.1076/phbi.38.6.16.5956

[2] http://samngoclinh.com/index.php?language=vi\&nv=about\&op=SAM-NGOC-LINH-VIET-NAM-JSC

[3] R. E. Wroslstad, R. M. Wiley. Analysis of total phenols and other oxidation substrates and antioxidant by means of Folin - Ciocalteu Reagent. Orthofer Lamuela-Ravents. Methods in Enzymology. 1999.

Vol.2009. P.152-178. DOI: 10.1016/S0076-6879(99)99017-1

[4] V.L. Singleton, R. Orthofer, R.M. Lamuela-Raventos. Analysis of total phenols and other oxidation substrates and antioxidants by means of Folin-Ciocalteu reagent. Methods in Enzymology. 1999. Vol.299. P.152-178. DOI: 10.1016/S0076-6879(99)99017-1

[5] G. I. Sobolkova, D. V. Kochkin, M. V. Titova, R. O. Grigoryev, A. G. Klyushin, A. M. Nosov. Obtaining and Study of Callus Cell Cultures of Ginseng Vietnamese Panax Vietnamensis Ha Et Grushv. Vestnik of North-Eastern federal university. 2018. T.65. No.3. P.39-49. ISSN 2222-5404; DOI: http://dx.doi.org/10.25587/SVFU.2018.65.14067 